\title{
Development and validation an HPLC - UV method for determination of esomeprazole and pirfenidone simultaneously in rat plasma: application to a drug monitoring study
}

\author{
Emrah Dural' ${ }^{10}$, Sema Tülay Köz 2,3 (D), Süleyman Köz $z^{4,5}$ (D) \\ 'Sivas Cumhuriyet University, Faculty of Pharmacy, Department of Pharmaceutical Toxicology, Sivas, Turkey \\ ${ }^{2}$ Sivas Cumhuriyet University, Faculty of Medicine, Department of Physiology, Sivas, Turkey \\ ${ }^{3}$ Bahçeșehir University, Faculty of Medicine, Department of Physiology, İstanbul, Turkey \\ ${ }^{4}$ Sivas Cumhuriyet University, Faculty of Medicine, Department of Nefrology, Sivas, Turkey \\ ${ }^{5}$ Medipol Health Group, Department of Nefrology, İstanbul, Turkey
}

ORCID IDs of the authors: E.D. 0000-0002-9320-8008; S.T.K. 0000-0002-3809-1070; S.K. 0000-0001-5036-0475

Cite this article as: Dural, E., Koz, S. T., \& Koz, S. (2021). Development and validation an HPLC - UV method for determination of esomeprazole and pirfenidone simultaneously in rat plasma: Application to a drug monitoring study. İstanbul Journal of Pharmacy, $51(1), 16-25$.

\begin{abstract}
Background and Aims: It has been observed that the combined treatment of esomeprazole and pirfenidone provides increased efficacy in the treatment of pulmonary fibrosis disease, recently. The aim of this study is to develop a simple, sensitive, and reliable high-performance liquid chromatography method to be used in drug monitoring to increase the effectiveness of esomeprazole and pirfenidone in treatment and to reduce their adverse effects.

Methods: Separation was conducted with a $\mathrm{C} 18$ reverse-phase column $(4.6 \mathrm{~mm} \times 250 \mathrm{~mm}, 5 \mu \mathrm{m})$ used as a mobile phase prepared with the phosphate buffer $\left(10 \mathrm{mM} \mathrm{KH}_{2} \mathrm{PO}_{4}\right.$ and $\left.10 \mathrm{mM} \mathrm{K}_{2} \mathrm{HPO}_{4}\right)$ and acetonitrile $(60: 40, \mathrm{v} / \mathrm{v})$ by an isocratic flow (1 $\mathrm{mL} / \mathrm{min}$ ). Mobile phase $\mathrm{pH}$ was adjusted to 3.0. Ultraviolet detection was accomplished at $305 \mathrm{~nm}$. The column oven was held at $35^{\circ} \mathrm{C}$ to ensure an efficient analytical separation.

Results: Analytical recovery of esomeprazole was between 92.43 and $105.36 \%$ and for pirfenidone it was found between 89.56 and $104.32 \%$. Accuracy values of esomeprazole and pirfenidone were determined between $(-2.90)-4.22$ and $(-4.45)$ -5.78 , respectively. Precision (RSD\%) was $\leq 7.89$. The quantification limit was determined as 0.58 and $0.36 \mathrm{ng} / \mathrm{mL}$. Plasma esomeprazole and pirfenidone levels were found as $0.87-8296.87 \mathrm{ng} / \mathrm{mL}(612.99 \pm 2212.20$, mean \pm standard deviation) and $0.45-238.60 \mathrm{ng} / \mathrm{mL}$ (61.44 \pm 76.35 , mean \pm standard deviation), respectively.

Conclusion: Unexpectedly high RSD values were observed in both plasma (360.88\%) and dose-rated results (89.61\%) of esomeprazole, and pirfenidone were thought to be related to individual metabolism differences.
\end{abstract}

Keywords: Esomeprazole, pirfenidone, rat plasma, method validation, HPLC-UV 


\section{INTRODUCTION}

Esomeprazole, 6-methoxy-2-[(S)-(4-methoxy-3,5-dimethylpyridin-2-yl)methylsulfinyl]-1H-benzimidazole (Figure 1a), is a part of the novel gastric proton pump inhibitors (Liu et al., 2017; Sebaiy, Hassan, \& Elhennawy, 2019). It provides decreased stomach acid secretion through inhibition of the $\mathrm{H}^{+}$/ $\mathrm{K}^{+}$- ATPase in the parietal cells of the stomach. It has better oral bioavailability than S-enantiomer. Esomeprazole is widely used in the treatment of many acid-related disorders such as peptic disease, gastroesophageal reflux, and in the prevention of the adverse reactions of non-steroidal anti-inflammatory drugs (Çelebi et al., 2016; Franke, Hepp, Harder, Beglinger, \& Singer, 2008; Johnson, 2003; Liu et al., 2017). In addition, remarkable results have been reported in various studies showing that its anti-fibrotic activities for both liver and lung recently (Eltahir \& Nazmy, 2018; Ghebre \& Raghu, 2016; Ghebremariam et al., 2015). Pulmonary fibrosis disease has a prevalence of 494.5 cases per 100,000 and an incidence of 93.7 cases per 100,000 (Raghu et al., 2014). Although this disease often occurs over the age of 60 , it may occur at earlier ages in familial idiopathic pulmonary fibrosis patients (Hodgson, Laitinen, \& Tukiainen, 2002; Marshall, Puddicombe, Cookson, \& Laurent, 2000; Nadrous, Myers, Decker, \& Ryu, 2005). The median survival rate is only 3-4 years from the time of diagnosis (Raghu et al., 2014).
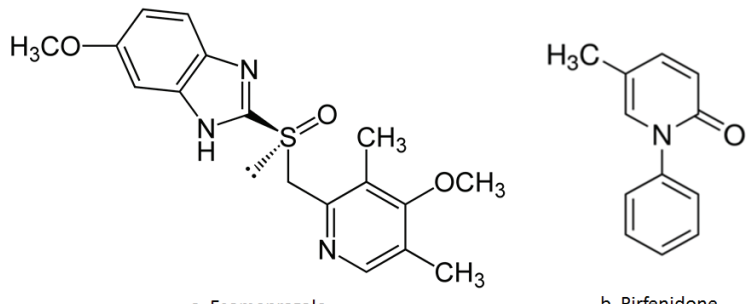

Figure 1. Chemical structures of esomeprazole (a) and pirfenidone (b).

Pirfenidone is a novel agent, 5-methyl-1-phenylpyridin-2-(1H)one, approved for mild to moderate idiopathic pulmonary fibrosis by FDA in 2014. It is a non-peptide, orally active small molecule $(185.22 \mathrm{~g} / \mathrm{mol})$ that is in use also as an antioxidant and anti-inflammatory agent. It is an orphan drug in Europe and Japan (Parmar, Desai, \& Vaja, 2014). A study which conducted a phase III multi-national clinical trial has shown that it has beneficial effects on patients with various stages of idiopathic pulmonary fibrosis disease. It has been reported that this agent could reduce lung fibrosis in drug-fibrotic in vivo studies, including the pirfenidone-hamster and the cyclophosphamide-mouse models (lyer et al., 1995; Kehrer \& Margolin, 1997). Although it is a commonly well-tolerated agent and has a favourable benefit-risk profile, gastrointestinal problems, photosensitivity reactions and rashes are its important adverse reactions that have been seen commonly (Khan, Shirkhedkar, Chaudhari, \& Pawara, 2019).

In this study, we aimed to develop a high performance liquid chromatography (HPLC) method for the monitoring of these agents from rat plasma based on solid phase extraction pretreatment due to the anti-fibrotic effects of esomeprazole and pirfenidone detected in both combined and individual treatments (Ghebremariam et al., 2015). There are some analytical methods developed for the determination of esomeprazole from different matrices in the literature. These are based on spectrophotometric (Prabu et al., 2008), capillary electrophoresis (Estevez, Flor, Boscolo, Tripodi, \& Lucangioli, 2014), gas chromatography (Raman, Reddy, Prasad, \& Ramakrishna, 2008), and liquid chromatography that coupled with an ultraviolet detector (Jain, Jain, Charde, \& Jain, 2011; Kayesh \& Sultan, 2015; Talaat, 2017), photodiode array detector (Sebaiy et al., 2019), and tandem mass spectrometry (Gopinath, Kumar, Shankar, \& Danabal, 2013). Also, some analytical methods were reported for the determination of pirfenidone from the different matrix which includes pharmaceutical dosage forms and plasma. These are spectrophotometric (Thorat, Padmane, Tajne, \& Ittadwar, 2016), spectrofluorometric (Sambhani \& Biju, 2018), capillary electrophoresis (Sotgia et al., 2020), high-performance thin layer chromatography (Thorat et al., 2016), gas chromatography (Ma et al., 2017), and HPLC with an ultraviolet detector (Bodempudi, Babur, \& Reddy, 2015; Parmar et al., 2014; Ravisankar, Anusha Rani, Devadasu, \& Devala Rao, 2014; Thorat et al., 2016), a photodiode array detector (Bodempudi et al., 2015) and a mass spectrometry detector (Tong et al., 2010; Wen et al., 2014) methods.

However, long analysis times, complex sample preparation protocols, and high sample quantities needed for analysis limit their use. At the same time low sensitivity, precision and accuracy of these methods may cause restriction of their use in the analyses. Although several liquid chromatographic methods were established for the determination of esomeprazole and pirfenidone, according to our investigation, there is no study that includes the simultaneous analysis of esomeprazole and pirfenidone by HPLC in rat plasma in the literature.

The aim of this study is to develop a simple, rapid and reliable HPLC analysis method for determination of esomeprazole and pirfenidone and to validate it in terms of linearity, repeatability, sensitivity, recovery, and robustness according to ICH Q2(R1) guidelines (ICH, 2005). This simple reproducible, efficient extraction method provided the determination of esomeprazole and pirfenidone levels from rat plasma without any process of the deproteinization and derivatization. It was used in the study of simultaneous monitoring of esomeprazole and pirfenidone levels in plasma samples from 14 rats treated by oral gavage. In addition, our study aimed to determine the plasma esomeprazole and pirfenidone concentrations of rats simultaneously by the chromatographic method to be developed. Also, it was aimed to analyze the relationship between drug doses and blood results statistically.

\section{MATERIAL AND METHODS}

\section{Chemicals and reagents}

Esomeprazole (Figure 1a) and pirfenidone (Figure 1b) analytical standards were purchased from Shandong Zhi Shang Chemical Co. Ltd. (Jinan, China) and Wuhan Benjamin Pharmaceutical Chemical Co. Ltd. (Wuhan, China), respectively. The Sep-Pac ${ }^{\circledast}$ Vac 1 cc (100 mg) solid-phase C18 cartridge was obtained from Waters (Dublin, Ireland). Ultragradient grade acetonitrile, 
ethanol and methanol were bought from Carlo-Ebra (Val-deReuil, France). Triethylamine ( $\geq 99 \%)$ was purchased from Sigma-Aldrich (Brussels, Belgium). Orthophosphoric acid $\left(\mathrm{H}_{3} \mathrm{PO}_{4}\right)$, sodium hydroxide $(\mathrm{NaOH})$, sodium chloride $(\mathrm{NaCl})$, potassium chloride $(\mathrm{KCl})$, disodium hydrogen phosphate $\left(\mathrm{Na}_{2} \mathrm{HPO}_{4}\right)$, dipotassium hydrogen phosphate $\left(\mathrm{K}_{2} \mathrm{HPO}_{4}\right)$ and potassium dihydrogen phosphate $\left(\mathrm{KH}_{2} \mathrm{PO}_{4}\right)$ which are analytical grade were bought from Merck (Darmstadt, Germany). Carboxymethyl cellulose was purchased from Biokim \& Wenda Chemicals (Izmir, Turkey). Bovine serum albumin was purchased from Solarbio Life Science (Beijing, China). Polytetrafluoroethylene (PTFE) membrane filter (47 mm diameter, $0.45 \mu \mathrm{m}$ pore size) was obtained from Millipore (Massachusetts, USA). An MRC ultrasonic bath (Harlow, UK), ACP-250H model, was used for the preparation of the mobile phase. Elga Purelab Water Purification System (Lane End, UK) was employed to supply ultra-pure water.

\section{Instrumentation and chromatographic parameters}

Agilent (Hewlett-Packard) 1100 series (California, USA) HPLC system equipped with a degasser (G1322A), a gradient-quad pump (G1311A), a manual injector (Rheodyne, 7725i) with a $20 \mu \mathrm{L}$ loop volume, a column thermostat (G1316A, Colcom), and an UV detector (G1314A, VWD) was used for separation and quantification of esomeprazole and pirfenidone in rat plasma. The system control and integration of the produced chromatographic data was achieved by a Chemstation 08.03 software (Palo Alto, USA). A stainless steel end-cap C18 reversephase (RP) analytical column ( $4.6 \mathrm{~mm} \times 250 \mathrm{~mm}$ i.d., 5 um p.s.) (USA) was successfully employed for the separation and quantitation of esomeprazole and pirfenidone.

Chromatographic conditions were determined after optimization studies on the analytical column, column thermostat temperature, mobile phase content and detector wavelength selection. $\mathrm{n}$ The best analytical separation result was achieved from the C18 RP ACE-3 column $(4.6 \mathrm{~mm} \times 250 \mathrm{~mm}$ i.d., $5 \mathrm{~mm}$ p.s.) out of 3 tested columns which were the RP-C18 Waters column ( $4.6 \mathrm{~mm} \times 250 \mathrm{~mm}$ i.d., $5 \mu \mathrm{m}$ p.s.) and the RP-C18 Zorbax column ( $4.6 \mathrm{~mm} \times 150 \mathrm{~mm}$ i.d., $3 \mu \mathrm{m}$ p.s.).

The minimum column back pressure ( $\leq 95$ bar) and enough peak resolution were gained after the oven temperature was set at $35^{\circ} \mathrm{C}$. Although different wavelengths $(220,246,254,270$ and $294 \mathrm{~nm}$ ) were tested for the determination of esomeprazole and pirfenidone in plasma, the highest peak sharpness and lowest matrix interference were obtained from $305 \mathrm{~nm}$. The UV spectrums of esomeprazole and pirfenidone were given in Figure 2.

The mobile phase buffer was prepared with $\mathrm{KH}_{2} \mathrm{PO}_{4}(10 \mathrm{mM})$ and $\mathrm{K}_{2} \mathrm{HPO}_{4}(10 \mathrm{mM})$ containing $0.1 \%$ triethylamine, then the $\mathrm{pH}$ was set at 3.0 by orthophosphoric acid $(0.1 \mathrm{M})$ and then filtered by a PTFE membrane. Then, this solution was mixed with acetonitrile $(60: 40, v / v)$ and then it was degassed with an ultrasonic bath, for 30 mins. The mobile phase was applied isocratically to the column with $1.0 \mathrm{~mL} / \mathrm{min}$ constant flow. Determination of analytes concentration in the quality control and rat blood samples were carried out using linear regression of response esomeprazole and pirfenidone peak area versus to their concentrations with the ultraviolet detector set at $305 \mathrm{~nm}$.

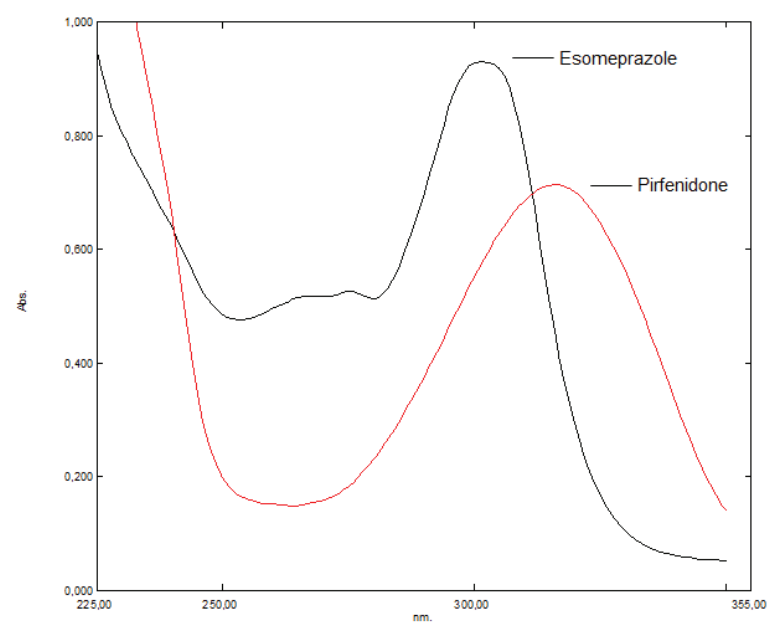

Figure 2. Overlapping UV spectra of esomeprazole and pirfenidone $(200 \mu \mathrm{g} / \mathrm{mL})$ that are between 255 and $355 \mathrm{~nm}$.

\section{Preparation of stock standard solutions and working standards}

Simulated plasma was used in all stages during the development of the solid-phase extraction (SPE) procedure and optimization and validation of this analytical method. It was prepared as follows: $20 \mathrm{mg}$ of $\mathrm{KCl}, 0.8 \mathrm{~g}$ of $\mathrm{NaCl}, 20 \mathrm{mg}$ of $\mathrm{KH}_{2} \mathrm{PO}_{4}$, $135 \mathrm{mg}$ of $\mathrm{Na}_{2} \mathrm{HPO}_{4}$ and $4 \mathrm{~g}$ of bovine serum albumin were weighed and dissolved in $100 \mathrm{~mL}$ of ultrapure water. The final pH was adjusted to 7.4 with $1 \mathrm{M} \mathrm{NaOH}$ or $1 \mathrm{M}$ orthophosphoric acid solutions (Mercolini, Mandrioli, Amore, \& Raggi, 2008). It was stored as $500 \mu \mathrm{L}$ in a $1.5 \mathrm{~mL}$ micro tube at $-18^{\circ} \mathrm{C}$ until use. The stock solution of esomeprazole and pirfenidone was prepared in methanol as $1 \mathrm{mg} / \mathrm{mL}$ and stored at $-18^{\circ} \mathrm{C}$ until use. It has been observed to be chemically stable for at least 1 month. Working solutions of esomeprazole and pirfenidone were prepared weekly from the main stock solution in methanol as $0.25,0.50,1.00,2.00$ and $5.00 \mu \mathrm{g} / \mathrm{mL}$ concentrations. Working standards were prepared daily, and they were used to add to simulated plasma samples prior to analysis. Quality control samples of esomeprazole and pirfenidone were freshly prepared in simulated plasma samples to provide concentrations of 25, 50, 100, 200 and $500 \mathrm{ng} / \mathrm{mL}$. Likewise, plasma quality control standards spiked with 25,100 and $500 \mathrm{ng} / \mathrm{mL}$ of esomeprazole and pirfenidone were prepared to measure the repeatability values of the method. Also, the same protocol was used in the preparation of limit of detection (LOD), limit of detection $(L O Q)$, recovery and robustness test samples.

\section{Preparation of quality control samples and real plasma samples}

Simulated plasma samples have been used in the forming of the quality control samples used during the development and validation process of this method. The collected real rat blood centrifuged at $4000 \mathrm{rpm}$ for 5 mins to separate the plasma. Quality control plasma and real patient plasma samples were stored at $-20^{\circ} \mathrm{C}$ until the analyses were carried out. Working solutions were checked chromatographically for purity before experiments, were utilized as quality control specimens and were checked for the stability before and after the injections of every sample set. 
The extraction procedure was carried out with a glass solidphase apparatus (12 wells) coupled with the vacuum pump according to the following steps:

i. In the initial step, the cartridge was conditioned with $1 \mathrm{~mL}$ acetonitrile;

ii. Equilibrium was achieved with $1 \mathrm{~mL}$ water and $1 \mathrm{~mL}$ methanol;

iii. The sample constituted $0.5 \mu \mathrm{L}$ plasma with $10 \mu \mathrm{L}$ ISTD (1 $\mathrm{mg} / \mathrm{mL}$ ) and $10 \mu \mathrm{L}$ esomeprazole and pirfenidone STDs (for quality control samples) was applied to the cartridge;

iv. The cartridge adsorbent was washed with $1 \mathrm{~mL}$ (two times) water;

v. The eluting was carried out with $1 \mathrm{~mL}$ acetonitrile (two times) for 5 mins at $75 \mathrm{kPa}$. All liquid in the cartridge was completely collected with a constant flow;

Finally, the collected extraction liquid (approximately $2 \mathrm{~mL}$ ) was evaporated under nitrogen. The remains, after being reconstituted in $200 \mu \mathrm{L}$ of the mobile phase, were injected into the analysis system as a volume of $20 \mu \mathrm{L}$.

\section{Validation of the analysis method}

The developed analytical method was validated in relationto its specificity and selectivity, linearity, accuracy and precision, sensitivity (LOD and LOQ), recovery and robustness. Intraday and inter-day validation protocol were applied considering reproducibility of the method to obtain accurate and precise measurements in accordance with ICH Q2R1 guidelines (ICH, 2005),

\section{Specificity and selectivity}

The method showed excellent chromatographic specificity without any endogenous interference in the retention times of esomeprazole and pirfenidone (4.2 and 6.1 mins, respectively) in simulated plasma. Blank (Figure 3a), spiked (Figure 3b) and real sample (Figure $3 c$ ), chromatograms were exhibited a high chromatographic resolution that conducted in 7.0 mins.

\section{Linearity}

After chromatographic conditions were established, matrixbased calibration curves of esomeprazole and pirfenidone were plotted concentrations over the concentration range $25-500 \mathrm{ng} / \mathrm{mL}$ versus peak-area of them. The calibration points $(\mathrm{n}=5)$, which were $25,50,100,200$ and $500 \mathrm{ng} / \mathrm{mL}$ composed of 3 individual replicates and were prepared by a standard addition method in simulated plasma and injected to HPLC.

\section{Accuracy and precision}

The accuracy defined as the relative error (RE\%) was calculated as the percentage difference between the added and found esomeprazole and pirfenidone quantity by 5 individual replicates both intraday and inter-day. The precision, which is defined as relative standard deviation (RSD\%), was calculated by five separate replicates of esomeprazole and pirfenidone both intraday and inter-day. Five replicated spiked samples were assayed intraday and inter-day at the three different concentrations $(25,100$ and $500 \mathrm{ng} / \mathrm{mL})$.

\section{Robustness}

The robustness test was performed with $200 \mathrm{ng} / \mathrm{mL}$ of esomeprazole and pirfenidone, which is the approximate medium concentration of the calibration interval. The response of the method over the changes in UV wavelength $( \pm 3 \mathrm{~nm}$ ) value, mobile phase flow rate $( \pm 0.1 \mathrm{~mL} / \mathrm{min})$, mobile phase solvent content $( \pm 5 \%)$ and, column temperature $\left( \pm 5^{\circ} \mathrm{C}\right)$ was evaluated.

\section{Sensitivity}

LOD and LOQ were calculated according to the $\mathrm{ICH}$ recommendations based on the standard deviation of the response, and the slope of the calibration graph. $25 \mathrm{ng} / \mathrm{mL}$ was used as the lowest calibration point in a sensitivity test of esomeprazole and pirfenidone.

$\mathrm{LOD}=3.3 \frac{\sigma}{\mathrm{s}} ; \mathrm{LOQ}=10 \frac{\sigma}{\mathrm{s}}(\sigma:$ The standard deviation of the response; S: The slope of the calibration curve).

\section{Recovery}

The recovery of the extraction procedure was calculated by comparing the results obtained from the extracted samples with the results of the unextracted samples which were directly prepared. This test was performed by adding 5 individual replicates of spiked samples at low, middle and high concentrations (25, 100 and $500 \mathrm{ng} / \mathrm{mL}$, respectively) of esomeprazole and pirfenidone. The extraction procedure was carried out as described before in the sample preparation step.

\section{Collection of plasma samples}

Approximately $1 \mathrm{~mL}$ of femoral vein blood sample was taken from Wistar Albino rat 2 hrs before the Wistar Albino rat whose plasma had a steady state concentration was put down. The rats included in this study were treated with esomeprazole (50 $\mathrm{mg} / \mathrm{kg} /$ day) and pirfenidone (100 mg/kg/day) by oral gavage prepared in $1 \mathrm{~mL}$ solution which has agents (esomeprazole and pirfenidone) dissolved in 1\% carboxymethyl cellulose and $10 \%$ ethanol. In this study, 14 blood samples were obtained from 14 individual rats involved in this research.

The rats in this study were treated by oral gavage with $1 \mathrm{~mL}$ of solution containing agents (esomeprazole and pirfenidone) dissolved in 1\% carboxymethyl and 10\% ethanol. One $\mathrm{mL}$ rats whole blood sample was put in a vacuum tube (BD Vacutainer ${ }^{\circledast}$ ) which contains $\mathrm{K}_{2}$ EDTA (5.4 mg) and was centrifuged at 3000 rpm for 10 mins on the same day. Then, the obtained plasma that had at least has $0.5 \mathrm{~mL}$ volume was transferred in a micro experiment tube and it was stored in a freezer at -86 C until the analysis. Plasma samples were analysed in less than 1 month.

Ethics committee approval: The ethical decision of this research was approved by the Animal Experiments Local Ethics Committee of Sivas Cumhuriyet University, with the 2016-03 decision number, dated on 14 January 2016. The research was conducted in accordance with the Declaration of Helsinki and its subsequent revisions.

Statistical analysis: All statistical analyses performed using the IBM Statistical Package for the Social Sciences (SPSS) 23.0. The Spearman non-parametric test was used to determine correlation. 


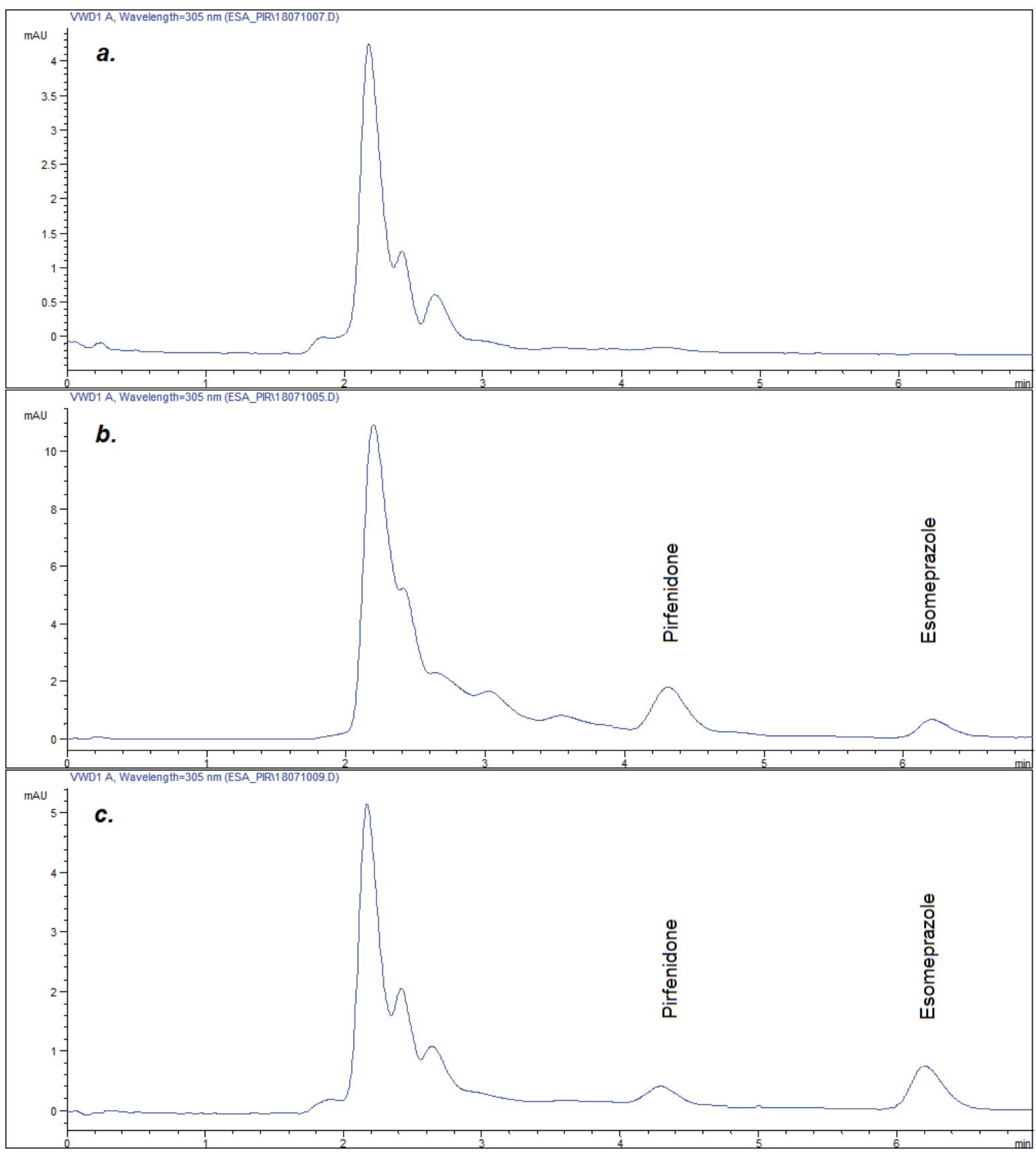

Figure 3. a. A chromatogram which belongs to blank-simulated plasma employed to prepare the quality control standards in all validation tests. b. A chromatogram sample containing $200 \mathrm{ng} / \mathrm{mL}$ esomeprazole and pirfenidone standards prepared with the standard addition method used as a quality control sample. c. A sample chromatogram belongs to a real plasma obtained from a rat treated with esomeprazole and pirfenidone.

\section{RESULTS AND DISCUSSION}

\section{Method validation}

Validation procedures were conducted considering $\mathrm{ICH}-$ Q2(R1) guidelines during the all of the test steps (ICH, 2005)

\section{Linearity}

The calibration curves of the esomeprazole and pirfenidone were constructed with excellent determination coefficient values which are $r^{2} \geq 0.9986$ at 5 points $(n=3)$ separately between 25 and $500 \mathrm{ng} / \mathrm{mL}$ concentrations by the standard addition method.
The correlation values of the method observed at the individual different 5 calibration points was quite good. The wide linear range has also had a positive effect on the use of the method. Since the obtained real blood results were shown very high standard deviation.

System suitability parameters showed that the method has a good resolution (Rs), selectivity (a), capacity factor ( $\left.k^{\prime}\right)$ and theoretical plate number $(N)$ for the determination of esomeprazole and pirfenidone successfully from rat plasma as it can see in Table 1. The column dead time was obtained by dividing 


\section{Table 1. Chromatographic characteristics, system suitability parameters and sensitivity values of the developed method.}

\begin{tabular}{|c|c|c|c|c|c|c|c|c|c|c|c|}
\hline 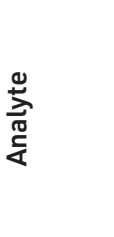 & 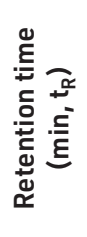 & 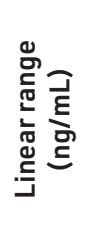 & 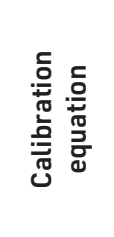 & 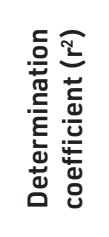 & 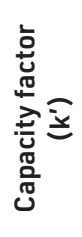 & 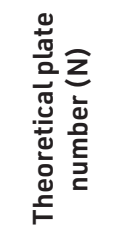 & 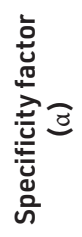 & 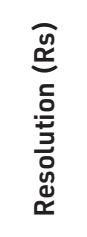 & $\vdash^{-}$ & 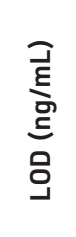 & 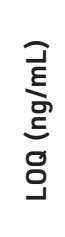 \\
\hline $\begin{array}{l}\text { Esome- } \\
\text { prazole }\end{array}$ & 4.2 & $\begin{array}{l}25- \\
500\end{array}$ & $\begin{array}{c}y= \\
226.69 x \\
+95.92\end{array}$ & 0.9986 & 1.91 & 7079.19 & 7.64 & 12.00 & 1.046 & 0.19 & 0.58 \\
\hline $\begin{array}{l}\text { Pirfeni- } \\
\text { done }\end{array}$ & 6.1 & $\begin{array}{l}25- \\
500\end{array}$ & $\begin{array}{c}y= \\
220.55 x \\
+ \\
11.238\end{array}$ & 0.9997 & 1.0 & 5831.41 & 4.00 & 7.16 & 1.125 & 0.12 & 0.36 \\
\hline
\end{tabular}

Equations: Capacity factor $\left(\mathrm{k}^{\prime}\right)=\frac{\mathrm{tR}-\mathrm{tc}}{\mathrm{to}} ;$ Theoretical plate number $(\mathrm{N})=16\left(\frac{\mathrm{tR}}{W \mathrm{t}}\right)^{2} ;$ Resolution $\left(\mathrm{R}_{\mathrm{s}}\right)=\frac{\sqrt{N}}{4} \frac{(\alpha-1)}{\alpha} \frac{k}{(k+1)} ;$ Specificity factor $(\alpha)=\frac{k 2}{k 1} ;$ Peak symmetry $\left(T_{f}\right)=\frac{a+\dot{k}}{2 a}$

Abbreviations: $t_{R}$ : retention time of the analyte peak; $t_{0}$ : retention time of mobile phase peak; Wt: peak width ; a: the distance from the leading edge of the peak to the peak midpoint ; $b$ : The distance from the back edge of the peak to the peak midpoint

the packed column volume by the flow rate (Column Spacing/ Dwell Time) and is given in Table I in minutes.

\section{Sensitivity}

The results of LOD and LOQ values, which were obtained from the measurement of individual 10 quality control (QC) samples, were demonstrated in Table 1. It was observed that the sensitivity values, especially LOQs, covered all the real plasma sample esomeprazole and pirfenidone results. Although the minimum concentrations of esameprazole and pirfenidone determined from plasma were 0.19 and $0.12 \mathrm{ng} / \mathrm{mL}$, it was observed that the LOQ values were determined as 0.58 and $0.36 \mathrm{ng} / \mathrm{mL}$, respectively. Therefore, the method is suitable for reliable analyzes for low concentrations of esomeprazole and pirfenidone.

\section{Precision and accuracy}

The data obtained from the accuracy and precision tests, performed in intraday and inter-day with quality control standards established in the blank plasma samples by standard addition method, showed low RSD\% values $\leq 7.59$ and $\leq 7.89 \%$ for interday and intraday respectively. Also low RE\% average values were observed between (-4.45)-5.78\% for inter-day and (-2.05)-5.69\% for intraday test values (Table 2). The obtained repeatability results showed that the method has excellent precision and accuracy values not only for intraday but also for inter-day analyses.

\section{Recovery}

Recovery test results which are done at 25, 100 and $500 \mathrm{ng} / \mathrm{mL}$ were between 89.56 and $105.36 \%$ with the results given in Table 2 . The method has a highly successful analytical result with the average recovery values at 97.44 and $93.83 \%$ for esomeprazole and pirfenidone, respectively. Recovery values obtained in the extraction procedure have demonstrated excellent efficiency. It was observed that the extraction procedure was not complicated and had no need for sophisticated instruments.

\section{Robustness}

No significant changes in the analytical signals were observed upon changing the UV wavelength value ( $\pm 3 \mathrm{~nm}$ ), mobile phase flow rate $( \pm 0.1 \mathrm{~mL} / \mathrm{min})$, mobile phase organic solvent ingredient $( \pm 5 \%)$, and column temperature $\left( \pm 5^{\circ} \mathrm{C}\right)$. All robustness results were given on Table 3 . In addition to that, change of analysts, columns, sources of chemicals and/or solvents did not lead to significant changes in chromatographic signals and results, either.

\section{Stability}

The stability of quality control (QC) simulated plasma samples $(25,100$ and $500 \mathrm{ng} / \mathrm{mL})$ prepared with a standard addition method and esomeprazole and pirfenidone analytes in stock solutions under several conditions were assessed. The stability of the stock solutions at room temperature was evaluated during 1, 2, 3 and 4 week periods. The stability test of freeze-thaw was carried out by three QC samples after operating five repeated freeze-thaw periods. The stability test in the long-term was carried out for 1, 2 and 3 months using QC samples maintained at $-20^{\circ} \mathrm{C}$. Neither significant decrease related to analytes peak area nor degradation which could be seen in chromatograms were observed in the concentration of esomeprazole and pirfenidone in three different conditions. The relative standard deviations which were observed in all sample results were less than $6.8 \%$.

These investigations have shown that there is not an investigation study in which esomeprazole and pirfenidone were simultaneously analyzed by a validated HPLC-UV method which has a solid phase extraction method in the literature. However, studies in the literature focusing separately on the analysis of esomeprazole and pirfenidone by HPLC are summarized below.

In Jain et al (2011) study, an HPLC method was developed for the determination of esomeprazole. Analytical separation was achieved by a C18 (4.6 mm x $150 \mathrm{~mm}$ i.d., $5 \mu \mathrm{m})$ column at 
Table 2. Confidence parameters that include intraday, inter-day precision and accuracy and recovery values. These results were obtained from individual samples $(n=5)$ formed in simulated plasma. Intraday reproducibility experiments were performed sequentially on the same day. Inter-day repeatability experiments were performed sequentially on consecutive 5 days.

\begin{tabular}{|c|c|c|c|c|c|c|c|c|}
\hline \multirow[b]{2}{*}{ Analytes } & \multirow{2}{*}{$\begin{array}{c}\text { Expected } \\
\text { concen- } \\
\text { tration } \\
(\mathrm{ng} / \mathrm{mL})\end{array}$} & \multicolumn{3}{|c|}{ Intra-day repeatability } & \multicolumn{3}{|c|}{ Inter-day repeatability } & \multirow[b]{2}{*}{$\begin{array}{l}\text { Recov- } \\
\text { ery\% }\end{array}$} \\
\hline & & $\begin{array}{c}\text { Observed } \\
\text { concentra- } \\
\text { tion } \pm \mathrm{SD}(\mathrm{ng} / \\
\mathrm{mL})\end{array}$ & $\begin{array}{l}\text { Precision } \\
\text { (RSD\%) }\end{array}$ & $\begin{array}{c}\text { Accuracy } \\
\text { (RE\%) }\end{array}$ & $\begin{array}{c}\text { Observed } \\
\text { concentra- } \\
\text { tion } \pm S D \text { (ng/ } \\
m L \text { ) }\end{array}$ & $\begin{array}{l}\text { Precision } \\
\text { (RSD\%) }\end{array}$ & $\begin{array}{c}\text { Accuracy } \\
\text { (RE\%) }\end{array}$ & \\
\hline \multirow{3}{*}{$\begin{array}{l}\text { Esome- } \\
\text { prazole }\end{array}$} & 25 & $2.85 \pm 0.31$ & 6.31 & 4.22 & $2.75 \pm 0.47$ & 4.59 & 2.49 & 92.43 \\
\hline & 100 & $4.49 \pm 0.92$ & 4.48 & -2.05 & $4.37 \pm 1.53$ & 7.43 & -2.90 & 94.54 \\
\hline & 500 & $49.15 \pm 1.13$ & 3.27 & -1.93 & $48.39 \pm 0.92$ & 4.33 & -0.78 & 105.36 \\
\hline \multirow{3}{*}{$\begin{array}{l}\text { Pirfeni- } \\
\text { done }\end{array}$} & 25 & $2.88 \pm 0.43$ & 7.89 & 5.69 & $2.85 \pm 0.58$ & 7.59 & 5.78 & 89.56 \\
\hline & 100 & $5.59 \pm 1.56$ & 5.53 & 3.65 & $4.37 \pm 1.53$ & 6.43 & -3.82 & 104.32 \\
\hline & 500 & $48.55 \pm 1.13$ & 4.76 & -0.93 & $48.39 \pm 0.92$ & 3.33 & -4.45 & 96.61 \\
\hline
\end{tabular}

Table 3. Robustness data of the described method representing as the RSD\% value. These results were obtained in the analysis of three variable points calculated by independent $(n=5)$ analyzes.

\begin{tabular}{|lcccc|}
\hline Analytes & $\begin{array}{c}\text { Mobile phases solvent } \\
\text { content }( \pm \mathbf{5} \%)\end{array}$ & $\begin{array}{c}\text { UV wavelength } \\
( \pm \mathbf{3} \mathrm{nm})\end{array}$ & $\begin{array}{c}\text { Flow rate } \\
( \pm \mathbf{0}) 1 \mathrm{~mL} / \mathrm{min})\end{array}$ & $\begin{array}{c}\text { Column temperature } \\
\left( \pm \mathbf{5}^{\circ} \mathrm{C}\right)\end{array}$ \\
\hline Esomeprazole & $3.82 \pm 0.12$ & $4.85 \pm 0.19$ & $2.81 \pm 0.14$ & $2.12 \pm 0.08$ \\
Pirfenidone & $4.65 \pm 0.14$ & $4.31 \pm 0.12$ & $1.92 \pm 0.07$ & $2.89 \pm 0.10$ \\
\hline
\end{tabular}

$25^{\circ} \mathrm{C}$. Acetonitrile and phosphate buffer $(\mathrm{pH}: 7.0)$ in the ratio of 50:50 ( $\mathrm{v} / \mathrm{v})$ was used as a mobile phase for HPLC. The flow rate was $0.5 \mathrm{~mL} / \mathrm{min}$. Quantitation was applied at $300 \mathrm{~nm}$. Method was found to be linear $(r=0.998)$ in the concentration range between $50-250 \mu \mathrm{g} / \mathrm{mL}$. The retention time was $5.661 \mathrm{~min}$. Mean recovery was $97.75 \%$. Accuracy was $<2.0$ (RSD\%) (Jain et al., 2011).

Kayesh and Sultan (2015) established an HPLC-ion pair method to determine esomeprazol in pharmaceutical formulation. As a mobile phase, tetrabutylammonium hydroxide $(7.7 \mathrm{mM})$ and $\mathrm{n}$-heptane sulfonic acid-Na salt (20 mM), acetonitrile and methanol (3:1:1, v/v) was isocratically applied to a C18 octadecyl-silica column (4.6 mm x 250 mm i.d., 5 mm p.s.) (Kayesh \& Sultan, 2015).

Sebaiy et al. (2019) developed a method for esomeprazole in human plasma. Protein precipitation was used for preparation of samples. Separation was carried out on a C18 column (4.6 $\mathrm{mm} \times 150 \mathrm{~mm}$ i.d., $5 \mu \mathrm{m}$ p.s.). Acetonitrile and $25 \mathrm{mM} \mathrm{KH_{2 }} \mathrm{PO}_{4}$ $(25: 75, \mathrm{v} / \mathrm{v})$ was used as a mobile phase. LOD was $40 \mathrm{ng} / \mathrm{mL}$ and LOQ was found as $130 \mu \mathrm{g} / \mathrm{mL}$. A DAD detector was set at $230 \mathrm{~nm}$. An aliquot of $200 \mu \mathrm{L}$ plasma was precipitated $\mathrm{MeOH}$. Then, the mixture was centrifuged at 5500 rpm for 15 mins. The obtained supernatant liquid was fitred with a 0.45 $\mu \mathrm{m}$ PTFE filter. Then, it was applied to the analytical system.
Method was found to be linear between $0.5 \mu \mathrm{g} / \mathrm{mL}$ to $50 \mu \mathrm{g} /$ $\mathrm{mL}(\mathrm{r}=1)$ concentrations. Recovery was between $98.38 \%$ and 101.14\%. Accuracy was observed as $-5.27 \%$. Precision (RSD\%) was observed between 0.78 and $15.79 \%$ (Sebaiy et al., 2019).

Talaat (2017) established a micellar HPLC-UV method employing a VP-ODS column ( $4.6 \mathrm{~mm} \times 150 \mathrm{~mm}$ i.d.) in separation. The mobile phase consisted of $0.1 \mathrm{M}$ sodium dodecyl sulfate, 10\% n-propanol, $0.3 \%$ triethylamine in $0.02 \mathrm{M}$ orthophosphoric acid (pH 3.5). The flow rate was $1.0 \mathrm{~mL} / \mathrm{min}$. The method was found to be linear between 1 and $20 \mu \mathrm{g} / \mathrm{mL}$. The UV detector was set at $280 \mathrm{~nm}$ (Talaat, 2017).

Ravisankar et al. (2014) established a RP-HPLC method to determinef pirfenidone in pharmaceutical dosage forms. Separation was carried out on a C18 column $4.6 \mathrm{~mm} \times 250 \mathrm{~mm}$ i.d., $5 \mu \mathrm{m}$ p.s.). The mobile phase was composed of acetonitrile: water (50:50, v/v). The flow rate was $1.0 \mathrm{~mL} / \mathrm{min}$ and UV detection was accomplished at $315 \mathrm{~nm}$. The method was found linear $(r=0.999)$ in the range of $2-10 \mu \mathrm{g} / \mathrm{mL}$. Recovery was found to be $99.60 \%$ to $99.80 \%$. Precision (RSD\%) was less than $2 \%$ (Ravisankar et al., 2014).

Parmar et al. (2014) developed an HPLC method for determination of pirfenidone from its pharmaceutical formulations. The separation was achieved isocratically on a reversed-phase C18 
Dural et al. Development and validation an HPLC - UV method for determination of esomeprazole and pirfenidone simultaneously in rat plasma: application to a drug monitoring study

column with a mobile phase consisting of acetonitrile: water $(35: 65, \mathrm{v} / \mathrm{v})$ at a flow rate of $0.7 \mathrm{~mL} / \mathrm{min}$. The UV detector was set at $317 \mathrm{~nm}$. The method was found linear between 0.2 and $5.0 \mathrm{\mu g} / \mathrm{mL}$. Recovery was in the range of 98 and $102 \%$ and precision was found $<2 \%$ (RSD\%) (Parmar et al., 2014).

In Bodempudi et al. (2015) study, an HPLC based chromatographic method was developed for the determination of pirfenidone in the drug substance. Separation was achieved with a C18 column (4.6 mm x 250 mm i.d., 5 m p.s.) using $0.02 \mathrm{M}$ $\mathrm{KH}_{2} \mathrm{PO}_{4}$ buffer and acetonitrile as mobile phase. The flow was $1.0 \mathrm{~mL} / \mathrm{min}$ and detection was achieved at $220 \mathrm{~nm}$. The method was found linear $\left(r^{2}=0.9985\right)$ between 47 and $382 \mathrm{ng} / \mathrm{mL}$. LOD was found $14 \mathrm{ng} / \mathrm{mL}$ and LOQ was calculated as $9.4 \mu \mathrm{g} /$ $\mathrm{mL}$ (Bodempudi et al., 2015).

In the study of Thorat et al. (2016) an HPLC method for the determination of pirfenidone from tablet dosage form was established. Analytical separation was carried out using an isocratic technique on a reversed phase C18 column (4.6 mm x $150 \mathrm{~mm}$ i.d., 5 m p.s.), with phosphate buffer: acetonitrile (pH 3.5) 72:28 $\mathrm{v} / \mathrm{v}$ as a mobile phase at flow rate $1 \mathrm{~mL} / \mathrm{min}$. The method was linear $(r=0.9964)$ between $5-70 \mu \mathrm{g} / \mathrm{mL}$. Recovery was between 99.2 and $101.3 \%$. Precision was found as $\leq 0.6751$ (RSD\%) (Thorat et al., 2016).

Wang et al. (2006) established an HPLC method for determination of pirfenidone as an analytical reagent in rat plasma. Rat plasma samples $(150 \mu \mathrm{L})$ were precipitated with 10\% (v/v) perchloric acid solution, then centrifuged. Obtained supernatant was applied to HPLC. This method was found to be linear between 0.15 and $76.67 \mu \mathrm{g} / \mathrm{mL}$. The separation was carried out on a C18 column (4.6 mm x $250 \mathrm{~mm}$ i.d., $5 \mu \mathrm{m}$ p.s.) using acetonitrile - water containing $0.2 \%$ acetic acid $(23: 77, \mathrm{v} / \mathrm{v}$ ) as a mobile phase at $1 \mathrm{~mL} / \mathrm{min}$ flow-rate. Detection was performed at $310 \mathrm{~nm}$. The accuracy (RE\%) was observed in ranges from (-2.6) to $7.9 \%$ and the precision (coefficient of variation) was found $\leq 4.5 \%$ (Wang et al., 2006).

In More et al. (2019) study, an HPLC analysis method for determination of pirfenidone was developed. The flow rate was $1 \mathrm{~mL} / \mathrm{min}$. The method was found linear ( $r=0.9989$ ) over the range of $5-25 \mu \mathrm{g} / \mathrm{mL}$. Recovery was between 98 to $100 \%$. The separation was applied with a C18 column $(4.6 \mathrm{~mm} \times 250 \mathrm{~mm}$ i.d., $5 \mu \mathrm{m}$ p.s.) at $30^{\circ} \mathrm{C}$ and a photodiode array detector was set at $317 \mathrm{~nm}$. Intraday and interday precision were found $\leq 0.65 \%$ (More, Dalwate, Chandramore, Jadhav, \& Jain, 2019).

\section{Measurement of esomeprazole and pirfenidone levels in rat plasma samples}

The developed HPLC method was employed for monitorization of the esomeprazole and pirfenidone levels in plasma samples belong to 14 rats that were treated with esomeprazole $(50 \mathrm{mg} / \mathrm{kg} /$ day) and pirfenidone (100 mg/kg/day). The esomeprazole and pirfenidone dose values to be applied to rats were determined according to the results of the previous studies in our laboratory.

Plasma samples were treated with the solid-phase extraction method described in Section 2.4 and made ready for HPLC analysis. No problem was observed in the samples for the quantification of the analytes. Additionally, peak purity showed that no analytical interference was encountered in the endogenous substances. The daily used esomeprazole and pirfenidone amounts, both their plasma levels and their dose-proportional plasma levels with the descriptive statistical analysis results for the obtained data were given in Table 4.

\section{Table 4. Sample results which involved rat plasma esomeprazole and pirfenidone concentrations that are unrevised and dose-proportional.}

\begin{tabular}{|c|c|c|c|c|}
\hline \multirow[b]{2}{*}{ 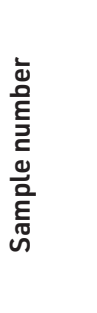 } & \multicolumn{2}{|c|}{$\begin{array}{l}\text { Esomeprazole } \\
(50 \mathrm{mg} / \mathrm{kg} / \text { day })\end{array}$} & \multicolumn{2}{|c|}{$\begin{array}{c}\text { Pirfenidone } \\
(100 \mathrm{mg} / \mathrm{kg} / \text { day })\end{array}$} \\
\hline & $\begin{array}{c}\text { Plasma } \\
\text { concen- } \\
\text { tration } \\
(\mathrm{ng} / \mathrm{mL})\end{array}$ & $\begin{array}{c}\text { Plasma } \\
\text { concen- } \\
\text { tration } \\
\text { /Dose } \\
\text { (ng/mL/ } \\
\mathrm{mg} \text { ) }\end{array}$ & $\begin{array}{c}\text { Plasma } \\
\text { concen- } \\
\text { tration } \\
(\mathrm{ng} / \mathrm{mL})\end{array}$ & $\begin{array}{c}\text { Plasma } \\
\text { concen- } \\
\text { tration } \\
\text { /Dose } \\
\text { (ng/mL/ } \\
\mathrm{mg})\end{array}$ \\
\hline S.01 & 27.89 & 0.56 & 4.08 & 0.04 \\
\hline S.02 & 3.49 & 0.07 & 1.36 & 0.01 \\
\hline S.03 & 8296.87 & 165.94 & - & - \\
\hline S.04 & 202.21 & 4.04 & 4.08 & 0.04 \\
\hline S.05 & 6.97 & 0.14 & 39.84 & 0.40 \\
\hline S.06 & 7.85 & 0.16 & 45.28 & 0.45 \\
\hline S.07 & 5.23 & 0.11 & 3.62 & 0.04 \\
\hline S.08 & 1.74 & 0.04 & 1.81 & 0.02 \\
\hline S.09 & 2.62 & 0.05 & 0.45 & 0.01 \\
\hline S.10 & 0.87 & 0.02 & 53.43 & 0.53 \\
\hline S.11 & 9.59 & 0.19 & 129.04 & 1.29 \\
\hline S.12 & 12.20 & 0.24 & 122.70 & 1.22 \\
\hline S.13 & 1.74 & 0.04 & 238.60 & 2.39 \\
\hline S.14 & 2.62 & 0.05 & 154.39 & 1.54 \\
\hline $\begin{array}{l}\text { Mean } \\
(\underline{x})\end{array}$ & 612.99 & 12.26 & 3.75 & 0.61 \\
\hline $\operatorname{SD}(\sigma)$ & 2212.19 & 44.24 & 11.14 & 0.76 \\
\hline $\mathrm{RSD} \%$ & 360.89 & 360.89 & 297.48 & 124.27 \\
\hline
\end{tabular}

Abbreviations: SD stands for "Standard Deviation"; RSD is "Relative Standard Deviation".

In this study, it was aimed to establish a method by focusing especially on the expected esomeprazole and pirfenidone concentrations in rat plasma. Therefore, these concentrations were taken into account in establishing the method and performing validation tests. For this purpose, in our study, a narrow linear range of 5 and $50 \mathrm{ng} / \mathrm{mL}$ was preferred for esomeprazole and pirfenidone, and a strong determination coefficient $(r \geq 0.9986)$ was obtained in both analytes. The LOQ obtained was found to be the lowest value ( $\leq 0.58 \mathrm{ng} / \mathrm{mL}$ ) detected in the literature. Chromatographic analysis was completed in 7 mins total without any endogenous intervention into the plasma sample. The value obtained from the precision test as $\leq 7.89 \%$ during the 
day and between days is compatible with the literature. Nice values between (-4.45) and 5.78 (RE\%) were obtained from intraday and inter-day accuracy tests. The average recovery values from the application of the preferred solid-phase extraction in preparing the samples for HPLC analysis were 93.83 to $97.44 \%$ for esomeprazole and pirfenidone, respectively. The data obtained from the robustness test carried out according to the change in mobile phase content, mobile phase flow rate, column temperature and UV value was $\leq 4.85$ (RSD\%).

Obtained plasma esomeprazole and pirfenidone and their dose rated results were statistically analyzed with Spearmen non-parametric test. The results showed that there was no statistically significant relationship between the analyzed results $(p>0.05)$

\section{CONCLUSION}

We strongly recommend this validated method to be used in routine therapeutic drug analysis of esomeprazole and pirfenidone. Also, it can be adapted to human plasma for monitoring overdose/poisoning caused by these drugs. Furthermore, since the method is established in the range of 25 to $500 \mathrm{ng} /$ $\mathrm{mL}$, it can be used in case of compliance problems with these drugs. The proposed method can be easily applied in routine therapeutic drug monitoring (TDM) studies of esomeprazole and pirfenidone. Also, it can be preferred in bioequivalence, pharmacovigilance and pharmacokinetics studies.

In this study, it was observed that both plasma-esomeprazole levels and plasma-esomeprazole concentration corrected according to daily drug doses $(\mu \mathrm{g} / \mathrm{mL} / \mathrm{mg}$ ) has very high RSD\% value which is $360.89 \%$. In addition, both plasma- esomeprazole levels and plasma-esomeprazole corrected according to daily drug doses $(\mu \mathrm{g} / \mathrm{mL} / \mathrm{mg})$ had significantly high RSD\% results which were 297.48 and $124.27 \%$, respectively. These results are both pharmacologically and toxicologically significant, and indicate that the potential to cause serious health problems for esomeprazole treatment.

Since these observed unexpected plasma esomeprazole and pirfenidone concentrations are thought to be related to the polymorphism of the CYP2C19 and CYP2A1 enzymes which are responsible for the biotransformation of esomeprazole and pirfenidone, the polymorphisms of the respective enzymes in the collected blood samples and its relationship with the plasma results obtained are planned to be investigated.

Acknowledgement: Authors would like to thank Sivas Cumhuriyet University, Faculty of Medicine Scientific Research Centre abbreviated as CÜTFAM for the invaluable open collaboration shown during this research.

Peer-review: Externally peer-reviewed.

Author contributions: Conception/Design of Study- E.D., S.T.K., S.K.; Data Acquisition- E.D., S.T.K.; Data Analysis/Interpretation- E.D.; Drafting Manuscript- E.D., S.T.K., S.K.; Critical Revision of Manuscript- E.D.; Final Approval and Accountability- E.D., S.T.K., S.K..

Conflict of Interest: The authors have no conflict of interest to declare.
Financial Disclosure: This research was supported by The Scientific Research Projects Support Programme of Sivas Cumhuriyet University (CÜBAP) under project number T-684.

\section{REFERENCES}

- Bodempudi, S.B., Babur, R., \& Reddy, K.S. (2015). Development and substantiation of a RP-HPLC method for monitoring of impurities in pirfenidone drug substance. American Journal of Analytical Chemistry, 06(13), 1019-1029.

- Çelebi, A., Aydın, D., Kocaman, O., Konduk, B.T., Şentürk, Ö., \& Hülagü, S. (2016). Comparison of the effects of esomeprazole $40 \mathrm{mg}$, rabeprazole $20 \mathrm{mg}$, lansoprazole $30 \mathrm{mg}$, and pantoprazole $40 \mathrm{mg}$ on intragastric $\mathrm{pH}$ in extensive metabolizer patients with gastroesophageal reflux disease. The Turkish Journal of Gastroenterology, 27(5), 408-414.

- $\quad$ Eltahir, H.M., \& Nazmy, M.H. (2018). Esomeprazole ameliorates $\mathrm{CCl} 4$ induced liver fibrosis in rats via modulating oxidative stress, inflammatory, fibrogenic and apoptotic markers. Biomedicine and Pharmacotherapy, 97, 1356-1365.

- $\quad$ Estevez, P., Flor, S., Boscolo, O., Tripodi, V., \& Lucangioli, S. (2014). Development and validation of a capillary electrophoresis method for determination of enantiomeric purity and related substances of esomeprazole in raw material and pellets. Electrophoresis, 35(6), 804-810.

- $\quad$ Franke, A., Hepp, C., Harder, H., Beglinger, C., \& Singer, M. V. (2008). Esomeprazole reduces gastroesophageal reflux after beer consumption in healthy volunteers. Scandinavian Journal of Gastroenterology, 43(12), 1425-1431.

- Ghebre, Y.T., \& Raghu, G. (2016). Idiopathic pulmonary fibrosis: Novel concepts of proton pump inhibitors as antifibrotic drugs. American Journal of Respiratory and Critical Care Medicine, 193(12), 1345-1352.

Ghebremariam, Y.T., Cooke, J.P., Gerhart, W., Griego, C., Brower, J.B., Doyle-Eisele, M., ... Rosen, G.D. (2015). Pleiotropic effect of the proton pump inhibitor esomeprazole leading to suppression of lung inflammation and fibrosis. Journal of Translational Medicine, 13(1), 1-20.

- $\quad$ Gopinath, S., Kumar, R.S., Shankar, M.B., \& Danabal, P. (2013). Development and validation of a sensitive and high-throughput LC-MS/MS method for the simultaneous determination of esomeprazole and naproxen in human plasma. Biomedical Chromatography, 27(7), 894-899.

Hodgson, U., Laitinen, T., \& Tukiainen, P. (2002). Nationwide prevalence of sporadic and familial idiopathic pulmonary fibrosis: evidence of founder effect among multiplex families in Finland. Thorax, 57(4), 338-342.

- $\quad$ ICH, I. (2005). Q2 (R1): Validation of analytical procedures: Text and methodology. In International Conference on Harmonization, Geneva.

- $\quad$ Iyer, S. N., Wild, J. S., Schiedt, M. J., Hyde, D.M., Margolin, S. B., \& Giri, S. N. (1995). Dietary intake of pirfenidone ameliorates bleomycininduced lung fibrosis in hamsters. The Journal of Laboratory and Clinical Medicine, 125(6), 779-785.

- Jain, D. K., Jain, N., Charde, R., \& Jain, N. (2011). The RP-HPLC method for simultaneous estimation of esomeprazole and naproxen in binary combination. Pharmaceutical Methods, 2(3), 167-172. Johnson, D. A. (2003). Review of esomeprazole in the treatment of acid disorders. Expert Opinion on Pharmacotherapy, 4(2), 253-264.

- $\quad$ Kayesh, R., \& Sultan, M. Z. (2015). A novel ion-pair RP-HPLC method for simultaneous quantification of naproxen and esomeprazole in pharmaceutical formulations. Journal of Chromatographic Science, 53(5), 687-693. 
- Kehrer, J.P., \& Margolin, S.B. (1997). Pirfenidone diminishes cyclophosphamide-induced lung fibrosis in mice. Toxicology Letters, 90(2-3), 125-132.

- $\quad$ Liu, R., Li, P., Xiao, J., Yin, Y., Sun, Z., Bi, K., \& Li, Q. (2017). A fast, sensitive, and high throughput method for the determination of esomeprazole in dog plasma by UHPLC-MS/MS: Application to formulation development of the compound preparation of esomeprazole. Journal of Chromatography B: Analytical Technologies in the Biomedical and Life Sciences, 1068-1069, 352-357.

- Ma, J., Sun, F., Chen, B., Tu, X., Peng, X., Wen, C. ... Wang, X. (2017). Tissue metabolic changes for effects of pirfenidone in rats of acute paraquat poisoning by GC-MS. Toxicology and Industrial Health, 33(12), 887-900.

- Marshall, R.P., Puddicombe, A., Cookson, W.O., \& Laurent, G.J. (2000). Adult familial cryptogenic fibrosing alveolitis in the United Kingdom. Thorax, 55(2), 143-146.

- Mercolini, L., Mandrioli, R., Amore, M., \& Raggi, M. A. (2008). Separation and HPLC analysis of 15 benzodiazepines in human plasma. Journal of Separation Science, 31(14), 2619-2626.

- More, S., Dalwate, S., Chandramore, N., Jadhav, V., \& Jain, A. (2019). Development of chromatographic method and validation for estimation of pirfenidone in bulk and pharmaceutical dosage form. International Research Journal of Pharmacy, 10(7), 45-50.

- $\quad$ Khan, M.M.G., Shirkhedkar, A., Chaudhari, P., \& Pawara, P.I. (2019). Analytical techniques for pirfenidone and terizidone: a review. International Journal of Pharmaceutical Chemistry and Analysis, 6(1), $1-5$.

- $\quad$ Nadrous, H.F., Myers, J.L., Decker, P.A., \& Ryu, J.H. (2005). Idiopathic pulmonary fibrosis in patients younger than 50 years. Mayo Clinic Proceedings, 80(1), 37-40.

- Parmar, V.K., Desai, S.B., \&Vaja, T. (2014). RP-HPLC and UV spectrophotometric methods for estimation of pirfenidone in pharmaceutical formulations. Indian Journal of Pharmaceutical Sciences, 76(3), 225-229.

- Prabu, S.L., Shirwaikar, A., Shirwaikar, A., Kumar, C.D., Joseph, A., \& Kumar, R. (2008). Simultaneous estimation of esomeprazole and domperidone by UV spectrophotometric method. Indian Journal of Pharmaceutical Sciences, 70(1), 128-131.

- $\quad$ Raghu, G., Chen, S.-Y., Yeh, W.-S., Maroni, B., Li, Q., Lee, Y.-C., \& Collard, H. R. (2014). Idiopathic pulmonary fibrosis in US Medicare beneficiaries aged 65 years and older: incidence, prevalence, and survival, 2001-11. The Lancet. Respiratory Medicine, 2(7), 566-572.

- Raman, N.V.V.S.S., Reddy, K.R., Prasad, A.V.S.S., \& Ramakrishna, K. (2008). Development and validation of a GC-MS method for the determination of methyl and ethyl camphorsulfonates in esomeprazole magnesium. Chromatographia, 68(7), 675-678.
Ravisankar, P., Anusha Rani, K., Devadasu, C., \& Devala Rao, G. (2014). A novel validated RP-HPLC method for the determination of pirfenidone in pharmaceutical dosage forms. Der Pharmacia Lettre, 6(5), 19-29.

Sambhani, N.G., \& Biju, V.M.N. (2018). A micelle-enhanced spectrofluorimetric determination of pirfenidone: application to content uniformity testing and human urine. Journal of Fluorescence, 28(4), 951-957.

- $\quad$ Sebaiy, M.M., Hassan, W.S., \& Elhennawy, M.E. (2019). Developing a high-performance liquid chromatography (HPLC) method for simultaneous determination of oxytetracycline, tinidazole and esomeprazole in human plasma. Journal of Chromatographic Science, 57(8), 724-729.

Sotgia, S., Fois, A.G., Sotgiu, E., Zinellu, A., Paliogiannis, P., Mangoni, A.A., \& Carru, C. (2020). Micellar electrokinetic capillary chromatographic determination of pirfenidone and 5-carboxy-pirfenidone by direct injection of plasma from patients receiving treatment for idiopathic pulmonary fibrosis (IPF). Microchemical Journal, 154, 104536.

Talaat, W. (2017). Bioanalytical method for the estimation of coadministered esomeprazole, leflunomide and ibuprofen in human plasma and in pharmaceutical dosage forms using micellar liquid chromatography. Biomedical Chromatography, 31(5).

Thorat, S.G., Padmane, S.P., Tajne, M.R., \& Ittadwar, A.M. (2016). Development and validation of simple, rapid and sensitive UV, HPLC and HPTLC methods for the estimation of pirfenidone in tablet dosage form. Journal of the Chilean Chemical Society, 61(2), 2978-2981.

- Tong, S., Wang, X., Jiang, H., Xu, X., Pan, Y., Chen, K.... Hu, G. (2010). Determination of pirfenidone in rat plasma by LC-MS-MS and its application to a pharmacokinetic study. Chromatographia, 71(7), 709-713.

Wang, Y., Zhao, X., Zhong, J., Chen, Y., Liu, X., \& Wang, G. (2006). Simple determination of pirfenidone in rat plasma via high-performance liquid chromatography. Biomedical Chromatography, 20(12), 1375-1379.

Wen, Y.-G., Liu, X., He, X.-L., Shang, D.-W., Ni, X.-J., Zhang, M. ... Qiu, C. (2014). Simultaneous determination of pirfenidone and its metabolite in human plasma by liquid chromatography-tandem mass spectrometry: application to a pharmacokinetic study. Journal of Analytical Toxicology, 38(9), 645-652. 